Aleksandra Jackiewicz (1)

Uniwersytet Warszawski

a.jackiewicz@uw.edu.pl

\title{
La reconstrucción de imágenes en la traducción poética: algunas reflexiones sobre las versiones españolas del poema $\dot{Z}$ ydom polskim de Władysław Broniewski
}

\begin{abstract}
Resumen:
El objetivo del artículo es indicar las dificultades de traducción con las que se enfrentan los traductores al reconstruir en los textos meta las imágenes presentes en el poema Żydom polskim de Władysław Broniewski. Se prestará una especial atención a la estrategia poética del autor que muestra unos profundos vínculos entre las circunstancias históricas y las experiencias personales y cuya finalidad es la poetización de la realidad observada. Nos proponemos realizar un estudio comparativo entre los versos de partida y sus dos versiones españolas que tiene como objetivo descubrir si la organización estilístico-formal de esta obra teñida de realismo histórico se ha conservado en los textos meta. La base del análisis la constituirá la concepción de la traducción como "experiencia de lo extranjero" (l'épreuve de l'étranger) y las tendencias deformantes del texto de partida que la imposibilitan, distinguidas por Antoine Berman.
\end{abstract}

Palabras clave: traducción, poesía, realismo histórico, Broniewski, Berman 


\begin{abstract}
:
The Reconstruction of Images in the Poetic Translation: Some Reflections on the Spanish Versions of the Poem Żydom polskim by Wladysław Broniewski The aim of the article is to show the difficulties which might be encountered by a translator who resolves to translate the historical realism depicted in the poem Żydom polskim by Władysław Broniewski. The contrastive study of the source text and its translations into Spanish will show to what extent the translators understood the uniqueness of this poetry and the strategy employed by the poet. The aim of such a juxtaposition is to determine whether the translation choices made by the translators reveal their awareness of the specific formal and stylistic structure of the poem. A starting point for the study is the theory of translation as "the experience of the foreign" ( $l$ 'épreuve de l'étranger) put forward by Antoine Berman, and the examination of twelve tendencies which deform the source text and might be found in every translation.
\end{abstract}

Keywords: translation, poetry, historical realism, Broniewski, Berman

La poesía de Władysław Broniewski, uno de los poetas polacos más importantes del siglo XX, se caracteriza por muchos elementos autobiográficos y es un ejemplo incomparable de actitud revolucionaria y de simplicidad. La especificidad de esta creación poética se debe al llamado "realismo histórico" que supone una relación muy fuerte y persistente de los versos con la totalidad de la experiencia personal del poeta y, asimismo, con los elementos de la realidad observada (Matuszewski, 1955: 18). Sin embargo, la estrategia poética de Broniewski no consiste en plasmar en sus versos la cotidianidad percibida desde una perspectiva subjetiva, sino en describir las circunstancias que le rodean de una manera más objetiva posible, poniendo de relieve el aspecto histórico. Como promotor de la corriente revolucionaria en la poesía polaca, Broniewski no solo quiso hablar del proletariado, sino también hablar como proletario, de ahí que leamos sus obras "hasta el día de hoy con emoción debido a la manera altamente artística, y a la vez sencilla y comunicativa, de expresar los sentimientos de desesperación ante la derrota y la esperanza en la victoria, compartidos por todos" (Jacek Kajtoch en: Suárez Recio, 1984: 9). 
La creación poética de Broniewski merece una atención especial también por el hecho de que en la historia de la traducción de la poesía polaca al español, el número de las versiones hispanas de sus poemas sigue siendo bastante escaso, comparándolo con otras obras de poetas polacos vertidas al español, lo cual, desde el punto de vista del lector polaco, podría resultar sorprendente. Los traductores hispanos que han decidido enfrentarse con la obra de Broniewski constituyen un grupo limitado, siendo probablemente una consecuencia de la maestría tanto lingüística como estructural de los textos originales. Así pues el propósito del presente artículo es indicar ciertas dificultades con las que tropiezan los traductores a la hora de trabajar con el poema $\dot{Z} y d o m$ polskim (A los judios polacos, A los judios polacos) que forma parte del poemario Bagnet na broń de 1943. El análisis comparativo del texto original y sus versiones españolas se basa en dos traducciones: la primera realizada por Gitta Maria Sten y Juan Rejano, publicada en México en la antología Poemas de la Nueva Polonia (1953); la segunda realizada por Andrzej Nowak y Francisco de Oraá, publicada en La Habana en Poesía polaca. Antología (1984).

Al reflexionar sobre el proceso de traducción desarrollado por los traductores, conviene recalcar las palabras de Juan Rejano que se considera a sí mismo como adaptador de las obras originales, lo cual expresa en la introducción a la antología Poemas de la Nueva Polonia:

Yo no he traducido estos poemas (...) los he recreado en lengua española. No conociendo la polaca, he tenido que valerme de las versiones literales que Gitta Sten ha puesto en mis manos, y en cada composición, después de escuchar su lectura varias veces en el idioma original, conocer su arquitectura interna y externa, e intuir el relámpago emocional que el autor quiso perpetuar entre ambas, me apresté a la faena de reconstruir ese pequeño mundo inaprehensible con la palabra musical y esencial, procurando ser leal al modelo, guardarle la mayor fidelidad. Nada - salvo en casos contadísimos - he añadido. Nada — salvo en excepcionales ocasiones - he restado. (Rejano, 1953: 5)

En cuanto a los problemas relativos a las cualidades formales de los textos de partida, cuyas traducciones forman parte de esta antología, 
ha sido ineludible hacer notar que en la mayoría de las traslaciones se ha dado prioridad a la transmisión del argumento a expensas de la transmisión del esquema métrico y rítmico de las obras analizadas, lo cual han admitido los mismos traductores:

Más atento a la vibración profunda de cada poema que a su vestidura formal, he prescindido de la rima, ya fuese directa o indirecta, en los que la llevan, para no agotar el rigor preceptivo ni caer en rigideces peligrosas que, en casos como éste, conducen siempre a la torpeza o la oscuridad. En cambio, he conservado el ritmo y la musicalidad allí donde ha sido posible y donde no - por fenómenos naturales de trasvase de un idioma a otro, de un idioma tan sutilmente rico como el polaco a un idioma tan rotundamente expresivo como el español—, los he sustituido por otros, más o menos familiares, pero siempre celosos del acento y de la tersura estética. (...) Tal acontecimiento no es una licencia, aunque lo parezca. $\mathrm{Ni}$ del autor, ni mía. Es una exigencia más de la versión, de la fidelidad al pensamiento poético. He preferido que éste prevalezca siempre y que prevalezca la exactitud del lenguaje en número y claridad, a cualquiera otra virtud. (Rejano, 1953: 5)

A la luz de esta advertencia, llama la atención la renuncia a la búsqueda de ritmos y rimas propias de la tradición poética de la lengua meta que puedan reflejar, cuando menos en parte, la precisión de los versos de partida. Los traductores han mostrado una evidente inclinación a verter los poemas originales a nivel lexical y oracional, suprimiendo, asimismo, el nivel formal que igualmente constituye el potencial semántico de cada obra poética. Por consiguiente, podemos constatar que se ha atenuado en las versiones hispanas el valor expresivo y estético propio de los versos polacos, entre ellos de los de Broniewski, por lo que es probable que estas no hayan provocado en los lectores hispanohablantes la misma reacción emotiva y estética que los poemas originales han despertado en la cultura fuente.

Por consiguiente, quisiéramos enfocarnos en este estudio en los problemas que derivan de la variedad de imágenes que Broniewski crea en sus versos con el fin de describir la realidad histórica que le rodea. Intentaremos verificar hasta qué punto las soluciones adoptadas 
en el proceso de traducción han conseguido reflejar el programa estilístico-formal desarrollado en los versos originales, dado que este atestigua la gran destreza del poeta en el manejo del lenguaje, así como también hace que sus versos sean únicos en su género. Finalmente, esperamos que esta indagación nos ayude a establecer en qué medida se le ha propiciado al receptor meta experimentar los atributos ajenos del mundo representado. Nos serviremos de la concepción del proceso de traducción como una experiencia de lo extranjero y las tendencias deformantes del texto de partida que la imposibilitan, distinguidas por Antoine Berman, haciendo hincapié en modificaciones tales como la racionalización, la aclaración, la expansión, el empobrecimiento cualitativo, el empobrecimiento cuantitativo, la destrucción de ritmos y la destrucción de sistemas vernáculos.

Volviendo al objeto de nuestro análisis, el poema Żydom polskim fue escrito en Jerusalén donde el poeta pasó dos años junto con el ejército polaco dirigido por el general Władysław Anders quien en 1943 fue destinado a Oriente Medio. Broniewski se unió al ejército de Anders en 1941, tras su liberación del campo de trabajos forzados en el norte de la Unión Soviética:

\section{Pamięci Szmula Zygielbojma}

Z polskich miast i miasteczek nie słychać krzyków rozpaczy, padli, jak hufiec bojowy, warszawscy obrońcy getta...

Słowa me we krwi nurzam, a serce w ogromnym płaczu, dla was, o Żydzi polscy, polski tułaczy poeta.

Nie ludzie, lecz psy okrwawione, i nie żołnierze, lecz kaci przyszli, by śmiercią porazić was, wasze dzieci i żony: gazem w komorach wydusić, wapnem w wagonach wytracić i szydzić z umierających, bezbronnych i przerażonych.

Lecz wyście podnieśli kamień, by cisnąć nim w kanoniera, który nastawiał działo, by dom wasz zburzyć do szczętu... 
Synowie Machabeuszów! i wy potraficie umierać, podjąć bez cienia nadziei walkę, we Wrześniu zaczętą.

Oto, co trzeba wyryć, jak w głazie, w polskiej pamięci: wspólny dom nam zburzono i krew przelana nas brata, łączy nas mur egzekucyj, łączy nas Dachau, Oświęcim, każdy grób bezimienny i każda więzienna krata.

Wspólne zaświeci nam niebo ponad zburzoną Warszawą, gdy zakończymy zwycięstwem krwawy nasz trud wieloletni: każdy człowiek otrzyma wolność, kęs chleba i prawo i jedna powstanie rasa, najwyższa: ludzie szlachetni.

(Broniewski, 1984: 215)

A la memoria de Szmul Zygielbojm

No se oyen los gritos desesperados de las ciudades y las aldeas polacas: como intrépida escuadra cayeron los defensores del Ghetto de Varsovia... Errante poeta de Polonia, mis palabras baño en la sangre, mi corazón en llanto inagotable, por vosotros, oh judíos polacos.

Hombres no, perros sangrientos; no soldados, verdugos

Vinieron con la muerte a golpearos y aniquilar a vuestros hijos y esposas en las cámaras de gas, con el calcio en los vagones, y a reírse de los que inermes morían en medio del espanto.

Mas vosotros habéis arrojado una piedra contra el artillero que apuntaba el cañón para arrasar vuestra casa. ¡Hijos de Macabeo! Vosotros sabéis morir, conducir sin desaliento la lucha que comenzó en septiembre.

Lo mismo que en el mármol debe quedar grabado en la memoria polaca: Nuestro común hogar destruían y nos hermanó la sangre derramada, 
nos une el muro de las ejecuciones, nos unen Dachau y Oswiecim, cada reja de prisión, cada tumba sin nombre.

Sobre Varsovia destruida un cielo común brillará para nosotros.

Cuando con la victoria finalicemos nuestro sangriento esfuerzo de largos años, cada hombre recibirá la libertad, un pedazo de pan y el derecho a la vida. Y habrá una sola raza, la más alta: la raza de los hombres nobles.

(trad. de Gitta Maria Sten, Juan Rejano en: Rejano, 1953: 15)

\section{En memoria de Szmul Zygielbo}

No se oyen llantos ni gritos en pueblo o ciudad polacos, los defensores del ghetto como héroes dieron su sangre... Sumerjo en sangre mi voz, mi alma en inmenso llanto por vosotros, oh, judíos polacos, yo, poeta errante.

Hombres no, perros sangrientos, verdugos y no soldados vinieron para mataros y a vuestras mujeres e hijos: ahogarlos en gas, con cal en los vagones quemarlos, burlarse de moribundos, inermes y asustadizos.

Pero piedras arrojasteis en contra del artillero que encañonó vuestra casa: no hay rastro de las paredes... Supisteis también morir, ¡hijos de los Macabeos! y asumir sin esperanza la lucha que abrió septiembre.

Esto es lo que hay que grabar, como en piedra, en la memoria: nos une la casa en ruinas y nuestra vertida sangre, nos hermana el paredón, Dachau, Oswiecim, cada fosa en donde no hay nombre escrito, las rejas de cada cárcel. 
Alumbrará el cielo a todos sobre Varsovia en escombros.

Cuando el esfuerzo sangriento de años el triunfo corone, cada hombre será libre, derecho y pan tendrán todos, surgirá una sola raza, suprema: la gente noble.

(trad. de Andrzej Nowak, Francisco de Oraá en: Suárez Recio, 1984: 92)

La obra trata del exterminio de los judíos y de los polacos en los campos de concentración de la Alemania nazi situados en los territorios de Polonia ocupados durante la Segunda Guerra Mundial. Es un manifiesto dedicado a la tragedia que vivieron ambas naciones a través del cual el poeta quiere identificarse con la raza judía y al mismo tiempo con la raza polaca, y así expresar su lamento por el mencionado martirio. A pesar de presentar un tono muy trágico, este poema es considerado uno de los más espléndidos, dado que manifiesta el realismo más íntimo del mundo observado. Además, el autor toma la palabra sobre el apego a la tierra natal y la preocupación por el futuro de la patria y de los más allegados (Matuszewski, 1955: 71). El carácter específico de esta obra lo subraya también su aspecto formal. Conviene notar que es un poema que consta de cinco estrofas, cada una formada por cuatro versos tónicos donde las sílabas se agrupan en pies iguales, pero varía el número de estas. No obstante, esta variedad de sílabas no surge de un modo "anárquico": el número de sílabas en el verso corresponde siempre a un múltiplo de las sílabas de un pie determinado (Bělič, 2000: 375-376). Una regularidad parecida la observamos también en el sistema de rimas empleado por el poeta. Cabe notar que Broniewski aplica a cada estrofa rimas cruzadas asonantes y consonantes, formando el esquema "abab".

Al reflexionar sobre la transmisión de estas peculiaridades de carácter métrico y rítmico a las versiones españolas, observamos que en la traducción de Sten y Rejano el número de sílabas oscila entre catorce y veinticuatro, de ahí que surja la destrucción de ritmos debido al aumento de la longitud de los versos y a la carencia del tonismo propio del texto de partida. Una incoherencia similar se produce también con el esquema de rimas ofrecido por los traductores, puesto que 
la mayoría de los versos meta no presenta ninguna rima, y se ofrecen tan solo tres parejas de rimas en las cláusulas de los versos españoles: una rima abrazada "polacas" - "polacos" y dos rimas gemelas "polaca" - "derramada" y "nosotros" - "años". Contrastando estas soluciones con el aspecto formal de la traducción de Nowak y Oraá, resulta que esta parece mucho más regular. En este caso, conviene resaltar que el número de sílabas en el texto meta oscila entre catorce y diecisiete, pero prevalecen los versos hexadecasílabos, de ahí que se mantenga la regularidad propia del texto original. De igual manera, queda perfectamente reflejado el esquema de rimas original, puesto que las rimas españolas corresponden a las rimas polacas tanto a nivel eufónico como a nivel icónico. Todas las estrofas meta presentan en las cláusulas de sus versos las rimas cruzadas asonantes, pues observamos las siguientes parejas de palabras: "polacos" - "llanto", "sangre" - "errante", "soldados" - "quemarlos", "hijos" - "asustadizos", "artillero" "Macabeos", "paredes" - "septiembre", "memoria" - "fosa", "sangre" - "cárcel", "escombros" - "todos", "corone" - "noble".

Pasando al cotejo detallado de los fragmentos seleccionados de los tres textos, quisiera detenerme en primer lugar en la dedicatoria Pamięci Szmula Zygielbojma, traducida como "A la memoria de Szmul Zygielbojm" (GMS/JR1) y "En memoria de Szmul Zygielbo" (AN/FO). En este caso, llama nuestra atención la figura de Szmul Zygielbojm, un político judío y miembro de la organización Bund, un movimiento de corte socialista creado a finales del siglo XIX en el Imperio ruso. Observamos aquí un error en la traducción de Nowak y Oraá, puesto que no aparece la forma nominativa del mencionado apellido judío Zygielbojm, lo cual puede provocar una confusión en el lector hispanohablante y hacer que este no perciba la importancia del personaje introducido por el autor. Desde luego, creemos que esta solución no es resultado de una insuficiente atención de los traductores

${ }^{1}$ Empleamos las siguientes abreviaturas de los nombres de los traductores: GMS/JR (Gitta Maria Sten y Juan Rejano), AN/FO (Andrzej Nowak y Francisco de Oraá). 
hacia el texto original, sino que es un ejemplo de los errores de edición que desgraciadamente suelen surgir en esta antología.

En segundo lugar, nos detendremos en el verso $Z$ polskich miast i miasteczek nie slychać krzyków rozpaczy, traducido por "No se oyen los gritos desesperados de las ciudades y las aldeas polacas" (GMS/JR) y "No se oyen llantos ni gritos en pueblo o ciudad polacos" (AN/FO). Aquí lo interesante y quizá lo problemático reside en la aliteración miast y miasteczek ("pueblos y pueblecitos") que no se conserva en ninguna de las traducciones, y como consecuencia se produce un empobrecimiento cualitativo a nivel eufónico que concierne a la omisión o sustitución de palabras o expresiones por otras unidades lingüísticas que no poseen la misma riqueza sonora, semántica o "icónica". De ahí que aparezcan pérdidas en la llamada "superficie de iconicidad", algo que se da tanto en prosa como en poesía, con lo cual se anula gran parte de su significación y de aquello que hace que el texto nos hable (Berman, 2005: 16). En consecuencia, se aminoran los atributos de la imagen representada en el verso de partida, y asimismo surge el riesgo de suavizar la sugestividad del mensaje. No obstante, debemos resaltar que los traductores mantienen el nivel icónico propio del fragmento analizado, pues las soluciones españolas "las ciudades y las aldeas" (GMS/JR) y "pueblo o ciudad" (AN/FO) pertenecen al mismo campo semántico.

A continuación, quisiéramos enfocarnos en el verso padli, jak hufiec bojowy, warszawscy obrońcy getta ..., traducido por "como intrépida escuadra cayeron los defensores del Ghetto de Varsovia..." (GMS/ JR) y "los defensores del ghetto como héroes dieron su sangre..." (AN/FO). Cabe observar que en la segunda traducción se omite la expresión original hufiec bojowy ("destacamento de combate") y en su lugar se emplea el sustantivo "héroes" (AN/FO) que está ausente en el verso de partida. Asimismo, no se transmite el adjetivo warszawscy ("de Varsovia"), y como consecuencia estamos ante una simplificación de la expresión polaca y, por consiguiente, ante la destrucción de sistemas vernáculos. Esta tendencia es una alteración de los elementos propios de la lengua vernácula en el proceso de traducción y constituye un ataque a la textualidad de la obra original que se observa, por 
ejemplo, en la eliminación de los diminutivos, la sustitución de verbos por series nominales o de verbos de acción por verbos con sustantivos, o en la falta de la transposición de significantes vernáculos (Berman, 2005: 21). Sin embargo, conviene subrayar que esta decisión de Nowak y Oraá es un producto por el esmero por el mantenimiento de la regularidad de las estrofas de llegada, así como por la conservación de las rimas en las cláusulas de los versos españoles.

Otro ejemplo interesante reside en el verso Stowa me we krwi nurzam, a serce $w$ ogromnym płaczu, traducido como "mis palabras baño en la sangre, mi corazón en llanto inagotable" (GMS/JR) y "Sumerjo en sangre mi voz, mi alma en inmenso llanto" (AN/FO). En este caso, llama la atención la locución stowa me we krwi nurzam que en ambas versiones se traduce de manera fiel, conservando la fuerza expresiva de la imagen original. Sin embargo, debemos aclarar que la traducción literal de Sten y Rejano que al emplear el sustantivo "palabras" provoca un aumento en la longitud del verso, mientras que la adopción de la palabra monosílaba "voz" por Nowak y Oraá, que no se relaciona tan estrechamente con el original, propicia conservar la concisión del verso meta, sin perturbar su significado.

En quinto lugar, quisiéramos enfocarnos en los versos przyszli, by śmiercia porazić was, wasze dzieci i żony: / gazem w komorach wydusić, wapnem w wagonach wytracić, traducidos por "Vinieron con la muerte a golpearos y aniquilar a vuestros hijos y esposas / en las cámaras de gas, con el calcio en los vagones" (GMS/JR) y "vinieron para mataros y a vuestras mujeres e hijos: / ahogarlos en gas, con cal en los vagones quemarlos" (AN/FO). Aquí nos interesa la manera de traducir tres verbos polacos: porazić ("paralizar"), wydusić ("ahogar") y wytracić ("exterminar"). Cabe observar que Nowak y Oraá transmiten todos los verbos mediante el empleo de las palabras "matar", "ahogar" y "quemar" que reflejan la idea original. Por su parte, Sten y Rejano deciden adoptar solo dos verbos: "golpear" y "aniquilar", sin traducir el mencionado término polaco wydusić. Esta omisión probablemente no influye tanto en la recepción del mensaje por el lector meta, no obstante, creemos que constituye un ejemplo de empobrecimiento cualitativo, pues produce una pérdida en la llamada 
"superficie de iconicidad", así como un empobrecimiento cuantitativo que provoca unas pérdidas a nivel lexical. Dado que en cada obra hay cierta proliferación de elementos y cadenas significantes, la "abundancia" propia del texto original también debería permanecer conservada en el proceso de traducir. La traducción que no respeta la multiplicidad de significantes aplicados por el autor, hace perder lo específico del original, y asimismo constituye un atentado contra la estructura lexical de la obra. De ahí que la imagen original expresada en estos versos puede quedar suavizada.

A continuación, nos ocuparemos del verso $i$ szydzić z umierających, bezbronnych i przerażonych, traducido como " $\mathrm{y}$ a reírse de los que inermes morían en medio del espanto" (GMS/JR) y "burlarse de moribundos, inermes y asustadizos" (AN/FO). En este caso, lo interesante es la manera de traducir el adjetivo polaco przerażony ("asustado" o "espantado") cuyo equivalente Sten y Rejano buscan en la locución "en medio del espanto", siendo una aclaración del original que consiste en explicar las sugerencias y las expresiones que el autor del texto de partida introduce en su obra. La solución ofrecida por Sten y Rejano hace también que el verso meta sea más largo y, asimismo, produce una pérdida relativa de la sencillez de la imagen construida por Broniewski. Por su parte, Nowak y Oraá se sirven del término "asustadizo" que alude a una persona "que se asusta con facilidad" $\left(\mathrm{DRAE}^{2}\right)$, con lo cual surge una alteración en cuanto al significado del original, pero permite al mismo tiempo mantener la regularidad del verso y la rima cruzada "hijos" - "asustadizos" en las cláusulas del segundo y el cuarto verso de dicha estrofa.

Otro ejemplo de omisión a la hora de traducir es el fragmento de Lecz wyście podnieśli kamień, by cisnać nim w kanoniera, traducido por "Mas vosotros habéis arrojado una piedra contra el artillero" (GMS/JR) y "Pero piedras arrojasteis en contra del artillero" (AN/FO). En este caso, notamos que en ambas versiones se suprime por completo el verbo polaco podnosić ("levantar"), y los traductores transmiten

\footnotetext{
${ }^{2}$ Empleamos la abreviatura DRAE para referirnos al Diccionario de la lengua española.
} 
solo la palabra ciskać que se traduce de manera literal, pues se emplean las formas "habéis arrojado" (GMS/JR) y "arrojasteis" (AN/ FO). Cabe también resaltar que al recurrir a este verbo en español, se emplean dos formas del pasado: la del pretérito perfecto y la del pretérito indefinido que, desde luego, no provocan ninguna alteración en cuanto a la expresividad de la imagen, no obstante, la primera conlleva un aumento en la longitud del verso, mientras que la segunda permite conservar el verso hexadecasílabo.

Para continuar, nos detendremos en el fragmento podjać bez cienia nadziei walkę, we Wrześniu zaczęta, traducido como "conducir sin desaliento la lucha que comenzó en septiembre" (GMS/JR) y "y asumir sin esperanza la lucha que abrió septiembre" (AN/FO). Aquí lo interesante reside en la expresión we Wrześniu zaczęta ("comenzada en Septiembre") donde el nombre del mes está escrito con mayúscula, con lo cual Broniewski le atribuye a dicho periodo un carácter simbólico, pues es una evidente alusión a la fecha del comienzo de la Segunda Guerra Mundial. Conviene señalar que este detalle no se transmite a los textos meta, pues leemos "comenzó en septiembre" (GMS/JR) y "abrió septiembre" (AN/FO), lo cual supone la destrucción de elementos propios de la lengua vernácula. Dicha modificación, a pesar de no parecer tan significativa desde el punto de vista de la expresividad de los versos de llegada, constituye una injerencia en la estrategia poética del autor, dado que puede originar un debilitamiento de la sugestividad de la imagen representada, además de conllevar un falseamiento de significado de la expresión original.

Una situación parecida la encontramos en el verso Oto, co trzeba wyryć, jak w głazie, $w$ polskiej pamięci, traducido como "Lo mismo que en el mármol debe quedar grabado en la memoria polaca" (GMS/ JR) y "Esto es lo que hay que grabar, como en piedra, en la memoria" (AN/FO). En este caso, nos detendremos en la expresión polskiej pamięci ("memoria polaca") que se traduce literalmente solo en la primera versión, mientras que en la segunda se suprime por completo el adjetivo polska ("polaca"), siendo otro ejemplo de tendencia del empobrecimiento cualitativo, ya que diluye la fuerza icónica del original. Dicha solución revela también la destrucción de sistemas vernáculos, 
y por ende la imagen meta adquiere un carácter más universal. Desde luego, la decisión de Nowak y Oraá se justifica en el mantenimiento de la concisión de los versos meta y de la rima cruzada "memoria" "fosa" en las cláusulas de los versos de la estrofa. Por otra parte, la traducción literal adoptada por Sten y Rejano también les permite a los traductores salvar la rima, en este caso, la rima gemela "polaca" "derramada", aunque el verso resulta mucho más extenso.

Un caso igualmente interesante lo presenta el fragmento łączy nas mur egzekucyj, łączy nas Dachau, Oświęcim, traducido como "nos une el muro de las ejecuciones, nos unen Dachau y Oswiecin" (GMS/ JR) y "nos hermana el paredón, Dachau, Oswiecim, cada fosa" (AN/ FO). Aquí llama nuestra atención la expresión original mur egzekucyj ("muro de ejecuciones") que se traduce literalmente en la versión de Sten y Rejano, pues leemos "el muro de las ejecuciones", por lo cual aumenta el número de sílabas en todo el verso, lo que conlleva la destrucción del ritmo. Por su parte, Nowak y Oraá se sirven del término "paredón" que alude a un "sitio, generalmente delante de un muro, donde se da muerte por fusilamiento" (DRAE), con lo cual consiguen mantener por completo la idea del original. Asimismo, gracias a tal decisión, resulta posible la conservación de la concisión del verso.

Otras soluciones que merecen nuestra atención, conciernen al fragmento każdy grób bezimienny $i$ każda więzienna krata, traducido como "cada reja de prisión, cada tumba sin nombre" (GMS/JR) y "en donde no hay nombre escrito, las rejas de cada cárcel" (AN/FO). Al reflexionar sobre las versiones meta de este verso, podemos constatar que en este caso estamos ante el fenómeno de racionalización que se refiere a las estructuras sintácticas del original y consiste en una recomposición de versos, reorganizándolos conforme a lo que establece la norma de la lengua meta. Esta tendencia puede hacer que el original pase de lo concreto a lo abstracto no solo mediante la modificación de su estructura, sino también, por ejemplo, al usar otros signos de puntuación, cambiar el orden de las palabras, sustituir verbos por sustantivos, evitar repeticiones, etc. Cabe observar que la expresión original każda więzienna krata ("cada reja de prisión") se traduce literalmente solo en la versión de Sten y Rejano, mientras que Nowak y Oraá la reformulan con el fin 
de mantener la rima cruzada "sangre" - "cárcel" en las cláusulas de los versos pares de la estrofa. Desde luego, dicho procedimiento no cambia significativamente la imagen original, pero puede considerarse una alteración de la estrategia poética del autor.

A continuación, quisiéramos enfocarnos en el fragmento każdy czlowiek otrzyma wolność, kęs chleba i prawo, traducido como "cada hombre recibirá la libertad, un pedazo de pan y el derecho a la vida" (GMS/JR) y "cada hombre será libre, derecho y pan tendrán todos" (AN/FO). En este caso, observamos que en la primera traslación las locuciones otrzyma wolność ("recibirá la libertad") y kęs chleba ("un pedazo de pan") se traducen al español de manera directa, mientras que el sustantivo prawo ("derecho") queda aclarado, ya que Sten y Rejano añaden la expresión "a la vida", que está ausente en el texto de partida, con lo cual todo el verso resulta más extenso y no se conserva el ritmo del poema. Además, esta decisión puede producir una pérdida de la sencillez del verso de Broniewski. Por su parte, en la versión de Nowak y Oraá notamos una simplificación de las locuciones originales, pues leemos las siguientes soluciones: otrzyma wolność ("será libre"), kęs chleba ("pan") y prawo ("derecho"). De esta manera, queda perfectamente ilustrada la intención del poeta y, asimismo, se evita el aumento en la longitud del verso.

Por último, nos ocuparemos de las traslaciones del fragmento $i$ jedna powstanie rasa, najwyższa: ludzie szlachetni, traducido por "Y habrá una sola raza, la más alta: la raza de los hombres nobles" (GMS/ JR) y "surgirá una sola raza, suprema: la gente noble" (AN/FO). Aquí observamos una situación análoga a la que acabamos de comentar que concierne a la locución ludzie szlachetni ("la gente noble"), traducida literalmente solo en la segunda versión, gracias a lo cual se salva la fuerza expresiva de la imagen ofrecida por el autor, se mantiene la concisión del verso, así como se crea la rima cruzada "corone" - "noble". Por su parte, Sten y Rejano optan de nuevo por la aclaración, puesto que deciden añadir al original la expresión "la raza de", repitiendo al mismo tiempo el sustantivo "raza", que aparece en la primera parte del verso, con lo cual todo el verso resulta más largo y por tanto pierde su 
sencillez. De esta manera, la aclaración no introduce nada nuevo a la imagen meta, enturbia incluso su identidad.

Dadas las observaciones arriba expuestas, concernientes a las dos traducciones del poema Żydom polskim de Władysław Broniewski, podríamos constatar que ambas parejas de traductores han mostrado un esfuerzo incuestionable en cuanto a la transmisión de los atributos del realismo histórico revelado en el texto original, tanto desde la perspectiva del aspecto formal como desde la perspectiva semántica, procurando así realizar una estrategia equivalente a la que hemos podido observar en los versos de partida. Desde luego, han surgido unos cambios en el plano métrico y rítmico del poema original, siendo un exponente de las tendencias deformantes de la destrucción de ritmo y la expansión que conciernen a la falta de rimas cruzadas y al aumento en la longitud de los versos de llegada, sobre todo en la traducción de Sten y Rejano. En lo referente a las transformaciones en el plano icónico, cabe señalar que las imágenes construidas por los traductores corresponden a las representaciones propias de los versos de partida, aunque es inevitable notar que tanto el lenguaje como los recursos estilísticos empleados en los textos meta se alejan de la destreza lingüística y estética ofrecida por el autor polaco, puesto que hemos podido observar tendencias de racionalización, aclaración, empobrecimiento cualitativo, empobrecimiento cuantitativo y la destrucción de sistemas vernáculos.

Ahora bien, a pesar de todas las transformaciones que ha experimentado la obra Żydom polskim, consideramos que la versión ofrecida por Andrzej Nowak y Francisco de Oraá, siguiendo la tipología de traducción poética elaborada por Efim Etkind, constituye un ejemplo de "traducción-recreación" (1982: 22-23). Se trata de una traslación que busca recrear el poema original en su conjunto semántico y formal, de manera que, ni el sentido se ve mermado por una literalidad que destruye la armonía estética $-\mathrm{y}$, por tanto, tampoco, el mismo sentido del poema-, ni la forma se ve ensalzada hasta el punto de traicionar el sentido del texto de partida (Soto Bueno, 2014: 95). Nuestro parecer se debe al hecho de que estos traductores se han esforzado por mantener el aspecto icónico y formal del poema sin ir más allá de la estética 
de Broniewski. Conviene recalcar que los autores de esta traducción han logrado ofrecerle al lector meta un texto que fluye de la misma manera que el original y que causa en él el mismo efecto afectivo y emotivo que experimenta el lector polaco. Por supuesto, es ineludible hacer constar que no se han salvado en el proceso de traducción todas las características del poema original, lo cual es consecuencia de una sobreinterpretación del texto, así como de una evidente propensión de los traductores a conservar la regularidad de los versos y del sistema de rimas que Broniewski propone en su obra. Por otra parte, no podemos olvidar que toda traducción conlleva unos sacrificios que surgen de las posibilidades expresivas y los géneros de la tradición poética de la lengua meta, de ahí que creamos que las soluciones adoptadas por Nowak y Oraá consiguen transferir al texto meta la realidad tanto lingüística como extralingüística representada en los versos de partida. Como contraste, la traducción ofrecida por Sten y Rejano constituye, según nosotros, un ejemplo de "traducción-aproximación" (Etkind, 1982: 19-22). Esta sucede cuando el traductor, convencido de que no es capaz de traducir el texto formalmente, da preeminencia en el texto meta al contenido de la obra original (Soto Bueno, 2014: 95). De ahí que la versión que se ofrezca representa un programa estético definido, pero que se relaciona solo hasta un cierto punto con el poema original, pues consigue transponer sus peculiaridades parcialmente, por ejemplo, mantiene rima sin metro, ritmo sin rima, etc. En el caso de la traducción analizada, resulta ineludible notar que sus autores han mostrado una indudable propensión a verter sobre todo el argumento de la obra, sin salvar sus peculiaridades métricas y rítmicas, lo cual probablemente se relaciona con la complejidad de la forma del texto original. Debemos admitir que Sten y Rejano se han esforzado por conservar la manera específica en la que Broniewski describe la realidad histórica por medio de la construcción de expresiones que se parecen a las que utiliza el poeta, pues una buena parte de los versos se traduce literalmente. De todas maneras, tenemos la sensación de que las soluciones empleadas en el proceso de traducción, por muy invasoras que hayan sido, sirven para recrear las imágenes de partida y dar un testimonio de la maestría y actualidad del poema por nosotros analizado. 


\section{Bibliografía}

BERMAN, A. (2005), "La traducción como experiencia de lo/del extranjero. La traduction comme épreuve de l'étranger", Cuadernos Pedagógicos, 2, Medellín, pp. 3-28.

BĔLIČ, O. (2000), Verso español y verso europeo. Introducción a la teoría del verso español en el contexto europeo, Instituto Caro y Cuervo, Santafé de Bogotá.

BRONIEWSKI, W. (1984), Wiersze i poematy, Wydawnictwo Łódzkie, Łódź.

Real Academia Española (RAE) (2016), Diccionario de la lengua española, [on-line] http://rae.es/, 29.12.2016.

ETKIND, E. (1982), Un art en crise. Essai de poétique de la traduction poétique, L'Age d'Homme, Lausanne.

MATUSZEWSKI, R. (1955), O poezji Władysława Broniewskiego, Państwowy Instytut Wydawniczy, Warszawa.

REJANO, J. (ed.) (1953), Poemas de la Nueva Polonia, Imprenta E. Muñoz Galache, México.

SOTO BUENO, D.R. (2014), "Bases para la traducción-recreación al español de poemas escritos en francés”, Entreculturas, 6, Málaga, pp. 89-114, http://hdl.handle.net/10630/7243.

SUÁREZ RECIO, M. (ed.) (1984), Poesía Polaca. Antología, Editorial Arte y Literatura, La Habana. 